\title{
Confirmation of clinical diagnosis in requests for prenatal prediction of SMA type I
}

\author{
J M Cobben, $M$ de Visser, H Scheffer, J Osinga, G van der Steege, C H C M Buys, \\ $G \mathrm{~J}$ van Ommen, $L$ P ten Kate
}

\begin{abstract}
The recent discovery of a major SMAlocus in the chromosomal region $5 q$ makes it possible to carry out prenatal DNA studies in families in which a child with SMA type I has been born. Since direct mutation analysis is not yet possible, the reliability of prenatal prediction of SMA type I usually depends on the certainty of the clinical diagnosis in the index patient. Sixteen requests were received for DNA studies in couples who had had a previous child with SMA type I. After re-evaluation, the performance of prenatal diagnosis was rejected in four cases. Among the other twelve families prenatal DNA analysis of chorion villus biopsies has been carried out in three families. In all three cases the fetus had inherited the high-risk haplotypes from both parents, and the parents chose to terminate the pregnancy. An illustration of the prenatal DNA studies in one family is given. The importance of confirmation of the diagnosis SMA type I before performing DNA studies is emphasised.
\end{abstract}

$(\Im$ Neurol Neurosurg Psychiatry 1993;56:319-321)

Department of Medical Genetics, University of Groningen J M Cobben H Scheffer $\mathrm{J}$ Osinga

$G$ van der Steege

C H C M Buys

L P ten Kate

Department of

Human Genetics,

University of Leiden

G J van Ommen

Department of Neurology, Academic

Medical Ventre of

Amsterdam, The

Netherlands

$M$ de Visser

Correspondence to:

Dr Cobben,

Department of Medical

Genetics,

Antonius Deusinglaan 4,

9713 AW Groningen,

The Netherlands

Received 20 March 1990

and in final revised form

7 July 1992.

Accepted 16 July 1992

Proximal spinal muscular atrophies (SMA) of childhood can be classified into three types on the basis of clinical criteria, SMA type I (Werdnig-Hoffmann disease), SMA type II (intermediate SMA) and SMA type III (Kugelberg-Welander disease). ${ }^{1}$ SMA type I is a lethal, autosomal recessive disease with a gene frequency of approximately $4-5 / 100,000 .^{2}$ The clinical picture is characterised by onset of hypotonia, progressive weakness, wasting of limb and trunk muscles and areflexia before six months of age. Children with classic SMA type I never gain the ability to sit, and death usually occurs within two years due to respiratory insufficiency. The diagnosis is based on the characteristic clinical picture, on signs of denervation in EMG studies and on the histopathological picture, that is, groups of junction with hypertrophic, usually predominantly type I, fibres. Inclusion and exclusion criteria for the diagnosis of SMA type I have recently been formulated. ${ }^{3}$ (Table)
In 1990 a major gene for the autosomal recessive types of SMA type I, II and III was localised in the chromosomal region 5q12q13. ${ }^{4-9}$ The availability of several highly polymorphic DNA-markers in this region permits prenatal prediction of SMA type I by DNA studies of chorionic villus or amniotic fluid cells in families with an affected child, making use of DNA from the affected child. ${ }^{1011}$ Caution is necessary, however, because of the probable genetic heterogeneity of SMA. ${ }^{5812}$

We analysed the process of confirmation of the clinical diagnosis in requests for prenatal diagnosis of SMA type I.

\section{Methods}

We restricted prenatal diagnosis to cases with an unequivocal diagnosis of SMA type I because of the reported genetic heterogeneity of SMA types II and III. ${ }^{12}$ In all cases the diagnosis SMA type I was evaluated by careful analysis of clinical data and re-evaluation of all available muscle biopsies.

When there was no doubt about the diagnosis of SMA type I, DNA from the parents and all healthy siblings was isolated by routine procedures, and DNA analysis was carried out with markers available for the chromosomal region 5q12-q13. ${ }^{1314-17}$

When both parents were informative for atrophic muscle fibres of either type in con-

\section{Table Criteria for diagnosis of SMA type I}

1 Clinical symptoms of anterior horn cell disease a-/hyporeflexia muscle atrophy
fasciculations

2 Early onset and progressive course age at onset $<1 / 2$ year age at death $<4$ year never able to sit unsupported

3 Creatine kinase normal CK $<10 x$ higher reference value)

4 Electromyographic study showing signs of anterior horn cell involvement

5 Muscle biopsy compatible with anterior horn cell disease 6 Exclusion criteria: no symptoms of other neurological systems no sensory loss no mental retardation

no arthrogryposis no evident facial involvement no other major organ involvement

In an isolated case all criteria except number 4 are obligate. In a familial case only criteria $1,2,3$ and 6 are obligate, while at least one affected family member (sibling) must meet the criteria for an isolated case. no central motor neuron symptoms 
markers on both sides of the SMA-locus, located between D5S6 and D5S112, the family was informed that prenatal diagnosis was possible with a specified reliability, dependent on the recombination distances of informative probes, the number of investigated affected and healthy siblings and the presence or absence of consanguinity. We incorporated in the calculations the current best estimate of $5 \%$ for the proportion of SMA type I families, which may not be due to an autosomal recessive gene on 5 q12-q13. In a particular family this a priori estimated figure of $5 \%$ was further modified for additional support for 5q-linkage, derived from the family itself. Finally, the chance of errors resulting from single and double recombinations between the SMA-locus and the informative DNA-markers was incorporated.

\section{Results}

Sixteen requests for prenatal diagnosis of SMA type I were received by our centre. In $4 / 16$ cases prenatal diagnosis was declined because the diagnosis did not fit classical SMA type I. We describe these 4 cases, indicating the differential diagnosis in the discussion.

\section{Case 1}

Case 1 was a male infant born with congeni-

\section{SMA54}

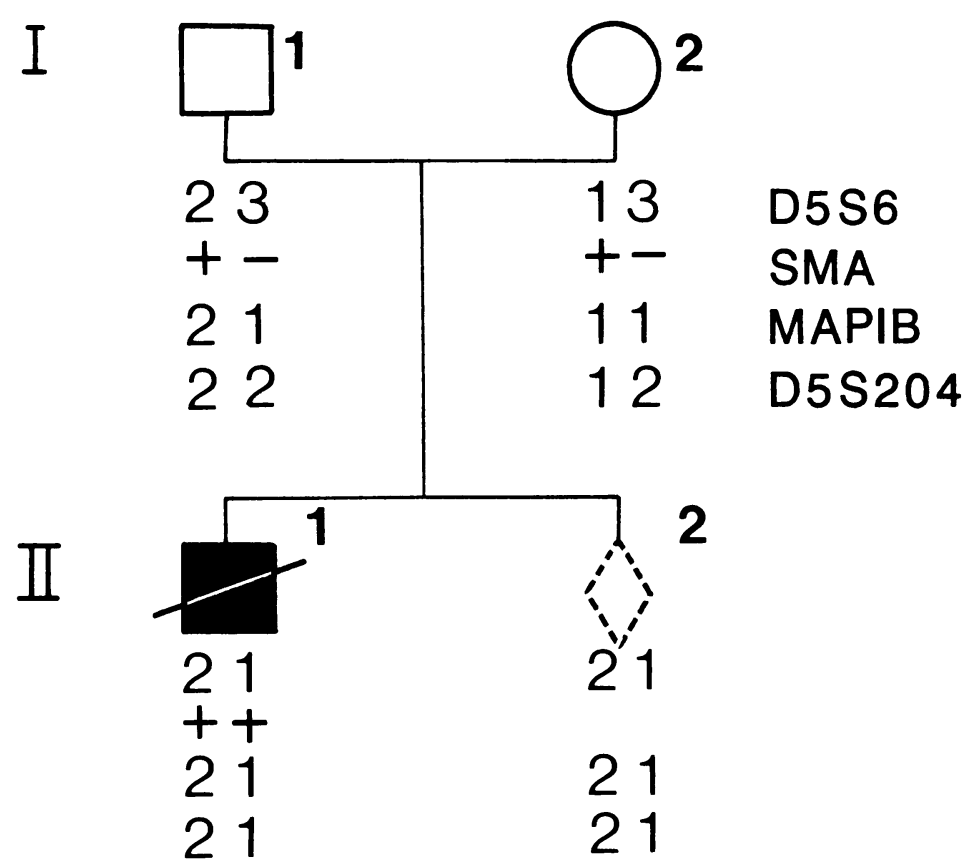

Figure Prenatal diagnosis in family SMA54. II-1 was a boy with SMA type I, who died in 1987. DNA was extracted from a frozen muscle biopsy, which had been stored. Both parents were informative for D5S6, the father informative for MAP1B and the mother for DSS204. The fetus I-2 inherited the same haplotype from the parents as the affected child. Assuming a genetic distance between $D 5 S 6$ and $M A P 1 B$ of $2-4 c M$ and between $M A P 1 B$ and 6741 of 4-6cM, and taking into account a 5\% proportion of a priori non-5q-linked $S M A$ I-families, the risk of the fetus being affected with SMA type I was calculated to be 92-93\%. The parents chose to terminate the pregnancy. $=$ male with SMA I. $\bigcirc=$ female, healthy. $\diamond=$ chorionic villus biopsy. $+=S M A$-allele. $-=$ normal allele. tal contractures of all joints, telecanthus, generalised hypotonia and signs of respiratory insufficiency. EMG-studies showed lively spontaneous muscle activity. Muscle biopsy revealed extensive endomysial fibrosis. After extensive clinical and biochemical studies bacteriology and virology, chromosome studies, radiological and ultrasound examinations, ECG and CT scanning of the cerebrum), no diagnosis could be made and the child died at the age of two months. Necropsy revealed an obvious decrease in the anterior horn cells with calcium deposits in these cells and the diagnosis of Werdnig-Hoffmann disease was made.

\section{Case 2}

Case 2 was a female infant born with congenital contractures of arms and legs, hygroma colli, a large atrial septal defect and generalised hypotonia with fasciculation of the tongue. She died when she was seven days old of respiratory insufficiency. Necropsy showed clear signs of anterior horn cell involvement, and it was concluded that the child had Werdnig-Hoffmann disease.

\section{Case 3}

This male child appeared normal at birth, but in the first year hypotonia became evident. The child could not sit unsupported. At one year EMG-studies were normal, but a muscle biopsy revealed groups of atrophic muscle fibres, lying amidst groups of normal to large calibre, predominantly type I, fibres. The diagnosis of spinal muscular atrophy was then made. At the age of 5, the child survived, but had respiratory insufficiency.

\section{Case 4}

Case 4 was a male infant, noted to be progressively hypotonic at age one. There was decreased facial muscle activity and knee jerks were preserved. EMG studies revealed no abnormalities. A muscle biopsy was performed and a diagnosis of WerdnigHoffmann disease was made. Re-evaluation of the muscle biopsy, however, showed only a slight variation in the size of the individual muscle fibres, without groups of atrophic fibres or other signs indicative of spinal muscular atrophy.

In the remaining 12 families DNA-studies were completed. In all families the parents were informative for DNA-markers flanking the SMA-gene. In 3 of the 12 families prenatal diagnosis by DNA-analysis of chorionic villus biopsy material was performed. In all three cases the fetus was probably affected with SMA type I (with a risk of $90 \%$, $92-93 \%$ and $94 \%$ respectively). The couples opted for selective abortion before the fifteenth week of pregnancy. An example of one family in which prenatal diagnosis was actually performed is represented in the figure.

\section{Discussion}

It is important to confirm the clinical diagnosis of SMA type I by all available methods to 
avoid errors in prenatal diagnosis of this disease. The SMA gene itself has not yet been found, so direct mutation DNA analysis is impossible.

The four cases in the families not offered prenatal diagnosis were considered not to have classic SMA type I.

Although contractures may develop during the course of SMA type I (case 1), the association of spinal muscular atrophy in children with congenital arthrogryposis may represent a separate disease entity. ${ }^{18}$

The congenital contractures, cardiac defect, hygroma colli and facial dysmorphia in case 2 are all unusual signs in SMA type I. Case 2 possibly represents a unique syndrome with signs of anterior horn disease, and resembles another case which has been documented. ${ }^{19}$ Although the first pathologist had diagnosed "Werdnig-Hoffmann disease" this term is ioften used erroneously, as a synonym for anterior horn cell disease. ${ }^{20}$

The clinical course in case 3 does not fit a diagnosis of SMA type I but could be consistent with SMA type II. Genetic heterogeneity for SMA type II is described with a proportion of cases not autosomal recessive inherited but either due to phenocopies or to autosomal dominant mutations. ${ }^{12}$ Progressive hypotonia in infancy (case 4) has a wide differential diagnosis and the diagnosis in this child is not yet clear.

The importance of confirming the clinical diagnosis SMA before embarking on DNA studies has recently been emphasised. ${ }^{320}$ It is difficult to define rigid diagnostic criteria. There will always be cases on which every expert agrees that it must be SMA type I, even though not all criteria (table 1) are met.

With the current availability of highly informative CA- or GT-repeat DNA-markers, parental uniformativeness for all markers in the 5q12-13 region will be rare, and did not occur in our cases. The DNA-studies will therefore reveal whether or not the fetus has inherited the same relevant portion of the parental chromosomes 5 as the preceding child with SMA did. A complicating factor is that a recombinant between the flanking markers of one or both parents may be detected in prenatal DNA-studies. A single recombination can greatly influence the risk of the fetus being affected. Before prenatal diagnosis, parents should be informed of the possibility and probability of results like these. The probabilities differ from family to family, depending on the precise family situation and on which DNA-markers are informative. In most families, however, as long as the gene has not been found, the reliability of prenatal testing for SMA type I is mainly dependent on the certainty of the clinical diagnosis in the index patient.

This work was supported by the Prinses Beatrixfonds (grant number 89-2949) and the Preventiefonds (grant number 28-1983).

1 Dubowitz V.Muscle disorders in childhood. Philadelphia; Saunders 1978:146-78.

2 Pearn J. The gene frequency of acute Werdnig-Hoffman disease (SMA type I). A total population survey in North-East England. $\mathscr{f}$ Med Genet 1973;10:260-5.

3 Munsat TL. Workshop report-International SMA collaboration. Neuromusc Dis 1991;1:81.

4 Brzustowicz LM, Lehner T, Castilla LH, et al. Genetic mapping of chronic childhood-onset spinal muscular atrophy to chromosome 5 q11·2-13.3. Nature 1990;344 540-1.

5 Gilliam TC, Brzustowicz LM, Castilla LH, et al. Genetic homogeneity between acute and chronic forms of spinal muscular atrophy. Nature 1990;345:823-5.

6 Melki J, Sheth P, Abdelhak S, Burlet P, et al. Mapping of acute (type I) spinal muscular atrophy to chromosome 5q12-q14. Lancet 1990;337:271-3.

7 Melki J, Abdelhak S, Sheth P, et al. Gene for chronic proximal spinal muscular atrophies maps to chromoproximal spinal muscular atroph

8 Sheth P, Abdelhak S, Bachelot MF, et al. Linkage analysis in spinal muscular atrophy, by six closely flanking markers on chromosome 5. Am $\mathcal{F}$ Hum Genet 1991;48:764-8.

9 Daniels RJ, Thomas NH, MacKinnon RN, et al. Linkage analysis of spinal muscular atrophy. Genomics 1992;12:335-9.

10 Daniels RJ, Suthers GK, Morrison KE, Thomas NH, Francis MJ, Mathew CG, Loughlin S, Heiberg A Wood D, Dubowitz V, Davies KE. Prenatal prediction of spinal muscular atrophy. 7 Med Genet 1992;29: 165-170.

11 Melki J, Abdelhak S, Burlet P, et al. Prenatal prediction of Werdnig-Hoffmann disease using linked polymorphic DNA-probes. ₹ Med Genet 1992;29:171-174.

12 Zerres K, Rudnik-Schöneborn S, Rietschel M Heterogeneity in proximal spinal muscular atrophy. Lancet 1990;336:749-50.

13 Kidd K, Bowcock AM, Schmidtke K, et al. Report of the DNA-committee and catalogues of cloned and mapped genes and DNA polymorphisms, Human Gene Mapping 10. Tenth International Workshop on Human Gene Mapping. Cytogenet Cell Genet 1989;51:622-947.

14 Lien LL, Boyce M, Kleyn P, et al. Mapping of human microtubule-associated protein $1 \mathrm{~B}$ in proximity to the spinal muscular atrophy locus at 5q13. Proc Natl Acad Sci USA 1991;88:7873-6.

15 Williamson R, Bowcock AM, Kidd K, et al. Report of the DNA committee and catalogues of cloned and mapped genes and DNA polymorphisms. Human Gene Mapping 10.5 (1990). Update to the Tenth International Workshop on Human Gene Mapping. Cytogenet Cell Genet 1990;55:457-778.

16 Morrison KE, Daniels RJ, Suthers GK, Flynn GA Francis MJ, Buckle VJ, Davies KE. High resolution Francis MJ, Buckle VJ, Davies KE. High resolution map around the spinal muscular atrophy locus

17 Mankoo BS, Sherrington R, De La Concha A, et al. Two microsatellite polymorphisms at the D5S39 locus. Nucl Acid Res 1990;19:1963.

18 Greenberg F, Fenolio KR, Hejtmancik JF, et al. X-linked infantile spinal muscular atrophy. Am $\mathcal{F}$ Dis Child 1988; 142:217-19.

19 Mitsumoto H, Adelman LS, Liu H-S. A case of congenital Werdnig-Hoffmann disease with glial bundles in spinal roots. Ann Neur 1982;11:214-16.

20 Dubowitz V. Chaos in classification of spinal muscular atrophies. Neuromusc Dis 1991;1:47-53. 